\title{
Motor-Skill Learning-Associated Gene Regulation in the Striatum: Effects of Cocaine
}

\author{
Ingo Willuhn' and Heinz Steiner*, I \\ 'Department of Cellular and Molecular Pharmacology, Rosalind Franklin University of Medicine and Science/The Chicago Medical School, \\ North Chicago, IL, USA
}

\begin{abstract}
Psychostimulant-induced molecular changes in cortico-basal ganglia-cortical circuits play a critical role in addiction and dependence. These changes include alterations in gene regulation particularly in projection neurons of the sensorimotor striatum. We previously showed that cocaine-induced gene regulation in such neurons is dependent on the behavior performed during drug action. Rats trained on a running wheel under the influence of cocaine for 4 days subsequently displayed greater c-fos induction by cocaine than untrained controls. This effect was selective for the sensorimotor striatum, which is known to mediate forms of motor learning. In the present study, we investigated whether this enhanced cellular responsiveness was associated with learning of wheel running or with prolonged running (exercising), by assessing c-fos inducibility after I, 2, or 8 days of training. Wheel training was performed after injection of cocaine (25 mg/ $\mathrm{kg}$ ) or vehicle, and c-fos induction by a cocaine challenge was measured $24 \mathrm{~h}$ later. Rats that trained under cocaine (but not vehicle) showed a greater c-fos response in the striatum compared to locked-wheel controls. This effect was present after the I-day training, peaked after 2 days, and dissipated by 8 days of training. Similar effects were found for substance P, but not enkephalin, expression. These changes in striatal gene regulation paralleled improvement in wheel running, which was facilitated by cocaine. Thus, these training-induced molecular changes do not appear to represent exercising effects, but may reflect motor learning-associated neuronal changes altered by cocaine. Such cocaine effects may contribute to aberrant motor learning implicated in psychostimulant addiction.

Neuropsychopharmacology (2006) 31, 2669-2682. doi: I 0. I038/sj.npp. I 300995; published online 4 January 2006
\end{abstract}

Keywords: c-fos; cocaine; dopamine; motor-skill learning; running wheel; striatum; substance P

\section{INTRODUCTION}

Psychostimulants produce numerous neuronal changes in the basal ganglia, and these are implicated in various aspects of addiction and dependence. These neuronal changes include alterations in gene regulation which are especially pronounced in projection neurons of the striatum (Hyman and Nestler, 1996; Harlan and Garcia, 1998; Torres and Horowitz, 1999; Berke and Hyman, 2000). These neurons are part of cortico-basal ganglia-cortical circuits (Alexander et al, 1986, 1990; Albin et al, 1989; Groenewegen et al, 1990). Drug-induced molecular changes in these circuits are thought to alter their function and contribute to behavioral changes (Berke and Hyman, 2000; Graybiel et al, 2000).

\footnotetext{
*Correspondence: Dr $\mathrm{H}$ Steiner, Department of Cellular and Molecular Pharmacology, Rosalind Franklin University of Medicine and Science/The Chicago Medical School, 3333 Green Bay Road, North Chicago, IL 60064, USA, Tel: + I 847578 8679, Fax: + I 847 578 3268, E-mail: Heinz.Steiner@rosalindfranklin.edu

Received 29 June 2005; revised 21 October 2005; accepted 21 October 2005

Online publication: 28 October 2005 at http://www.acnp.org/citations/ Npp I02805050423/default.pdf
}

Psychostimulant-induced neuronal changes are well studied in limbic cortico-basal ganglia circuits through the ventral striatum, which are implicated in motivational aspects of drug taking (eg Pierce and Kalivas, 1997; White and Kalivas, 1998; Wolf, 1998; Robinson and Berridge, 2000; Everitt et al, 2001; Nestler, 2001; Kelley, 2004). However, the most profound changes in gene expression induced by a range of addictive drugs are found in dorsal regions of the striatum (Steiner and Gerfen, 1993; Harlan and Garcia, 1998; Berke and Hyman, 2000). Little is known regarding the functional consequences of these neuronal changes.

In order to better define which functional domains are altered by such drugs, we have mapped gene regulation effects of psychostimulants across the striatum (Willuhn et al, 2003; Yano and Steiner, 2005a, b). In these studies, we used sampling areas (sectors) delineated mostly based on their principal cortical inputs to determine the corticostriatal circuits affected (Willuhn et al, 2003). Assessed were changes in the expression of a number of genes, including transcription factors (c-fos, zif 268), a synaptic plasticity factor (Homer 1a), neuropeptides, and others. Our results demonstrate that both acute molecular effects of cocaine, as well as neuroadaptive changes after repeated cocaine treatment are maximal in specific dorsal striatal sectors of 
the middle to caudal striatum (Willuhn et al, 2003). A principally similar topography was found for gene regulation effects of acute and repeated treatment with the psychostimulants methylphenidate (Brandon and Steiner, 2003; Yano and Steiner, 2005a,b) and amphetamine (Meredith and Steiner, 2006). In all of these studies, the most affected striatal sectors are parts of the sensorimotor striatum that receive convergent cortical inputs predominantly from the medial agranular (premotor) and sensorimotor cortex (see Willuhn et al, 2003).

Neuronal activity in sensorimotor corticostriatal circuits is correlated with specific aspects of motor performance (eg West et al, 1990; Tschanz et al, 1991; Haracz et al, 1993; Carelli et al, 1997). Moreover, recent studies showed that such activities are modified during the process of motor learning (eg Carelli et al, 1997; Jog et al, 1999; Miyachi et al, 2002; Brasted and Wise, 2004). Psychostimulants affect many of the same signal transduction pathways that are important for synaptic plasticity and learning (eg Berke and Hyman, 2000), and it has been proposed that psychostimulant-induced changes in molecular mechanisms of learning may result in aberrant motor learning, and that these effects are mediated by the sensorimotor striatum (Berke and Hyman, 2000; Everitt et al, 2001). We therefore investigated whether cocaine and behavioral training would interact to alter gene regulation in the sensorimotor striatum. Rats trained on a running wheel under the influence of cocaine were compared with cocaine-treated nonrunning controls (Willuhn et al, 2003). Our results showed that, after 4 days of training, a cocaine challenge produced a greater c-fos response in sensorimotor sectors of wheel-trained rats than in nonrunning controls, indicating that c-fos inducibility was modified by the association of behavioral training and cocaine treatment (Willuhn et al, 2003).

In the present study, we further investigated these cocaine-induced, training-related molecular changes in the striatum. We examined whether these changes were produced by extended running (exercising; eg MacRae et al, 1987; McCloskey et al, 2001) or were associated with the beginning of the training when rats learn to run on the wheel, by comparing the effects of different training durations (1- vs 2- vs 8-day training) on c-fos induction. Our results show that enhanced striatal c-fos inducibility is found during a limited time window at the beginning of the training, and only when training occurs under the influence of cocaine, consistent with the notion that cocaine can alter motor learning-associated molecular changes in the striatum.

\section{MATERIALS AND METHODS}

\section{Subjects}

Male Sprague-Dawley rats (175-200 g at the beginning of the experiments; Harlan, Madison, WI) were housed in groups of two to three under standard laboratory conditions. They had free access to food and water, and were maintained under a $12: 12 \mathrm{~h}$ light/dark cycle (lights on at 0700 hours). All procedures met the NIH guidelines for the care and use of laboratory animals and were approved by the Rosalind Franklin University Animal Care and Use Committee.

\section{Behavioral Training and Drug Treatment}

Rats were trained on a running wheel on 1,2 , or 8 days (performed as three independent studies). The training was carried out in their housing room between 1000 and 1600 hours. The rats received an injection of cocaine (cocaine hydrochloride; Sigma, St Louis, MO; $25 \mathrm{mg} / \mathrm{kg}$, i.p.; in $0.02 \%$ ascorbic acid, $1 \mathrm{ml} / \mathrm{kg}$; $\mathrm{C}$ groups), or vehicle (V groups), and were placed either on a running wheel ('running'; R) or on an identical wheel that was immobilized ('locked'; L), for $1 \mathrm{~h}$. After the training, the rat was returned to the home cage. The wheels (Wahmann Company, Baltimore, MD) consisted of a rotating chamber formed by a metal wall with an attached wire mesh floor (diameter, $35 \mathrm{~cm}$; width, $11 \mathrm{~cm}$ ), and a stationary metal wall with an access opening (Figure 1a). After the rat was placed inside the wheel, the opening was blocked. Thus, the animal was free to run, but could not leave the wheel during the training session. The wheels had a mechanical counter that recorded full revolutions. In addition, the behavior in the wheel was videotaped and analyzed by an experimenter blind to the treatment.

A day after the training, the rats were transferred to an adjacent room, where they received a challenge injection of cocaine $(25 \mathrm{mg} / \mathrm{kg}$ ), or vehicle (groups $\mathrm{RC} / \mathrm{C}, \mathrm{LC} / \mathrm{C}, \mathrm{RV} / \mathrm{V}$, $\mathrm{LV} / \mathrm{V} ; n=5-9$ each), and were killed $30 \mathrm{~min}$ later. After the injection, the rat was placed into the arena of an activity monitor $(43 \times 43 \mathrm{~cm}$; Truscan, Coulbourn Instruments, Allentown, PA). Ambulatory distance and repetitive local movements ('stereotypy 2' counts) were measured for the entire 30 -min survival period.

\section{In Situ Hybridization Histochemistry}

The rats were killed with $\mathrm{CO}_{2}$. The brains were rapidly removed, frozen in isopentane cooled on dry ice, and stored at $-20^{\circ} \mathrm{C}$ until sectioning. Coronal sections $(12 \mu \mathrm{m})$ through the striatum were cut on a cryostat. The sections were thawmounted onto glass slides (Superfrost/Plus, Daigger, Wheeling, IL), dried on a slide warmer, and prepared for in situ hybridization histochemistry as described earlier (Steiner and Kitai, 2000). Oligonucleotide probes (48-mers; Life Technologies, Rockville, MD) were labeled with $\left[{ }^{35} \mathrm{~S}\right] \mathrm{dATP}$ (Steiner and Kitai, 2000). The probes had the following sequence: c-fos, complementary to bases 207-254, GenBank accession number X06769; substance P, bases 128-175, X56306; dynorphin, bases 862-909, M10088; enkephalin, bases 436-483, M28263. Approximately $3 \times 10^{6} \mathrm{cpm}$ of labeled probe in $100 \mu \mathrm{l}$ of hybridization buffer was added to each slide (Steiner and Kitai, 2000). The sections were coverslipped and incubated at $37^{\circ} \mathrm{C}$ overnight. After incubation, the slides were first rinsed in four washes of $1 \times$ saline citrate $(150 \mathrm{mM}$ sodium chloride, $15 \mathrm{mM}$ sodium citrate), and were then washed three times $20 \mathrm{~min}$ each in $2 \times$ saline citrate $/ 50 \%$ formamide at $40^{\circ} \mathrm{C}$, followed by two washes $30 \mathrm{~min}$ each in $1 \times$ saline citrate at room temperature. After a brief water rinse, the sections were air-dried and apposed to X-ray film (BioMax MR-2, Kodak) for 4-10 days.

\section{Analysis of Autoradiograms}

Gene expression was assessed in coronal sections from four rostrocaudal levels, a rostral (at $\sim+1.6 \mathrm{~mm}$ relative 
a
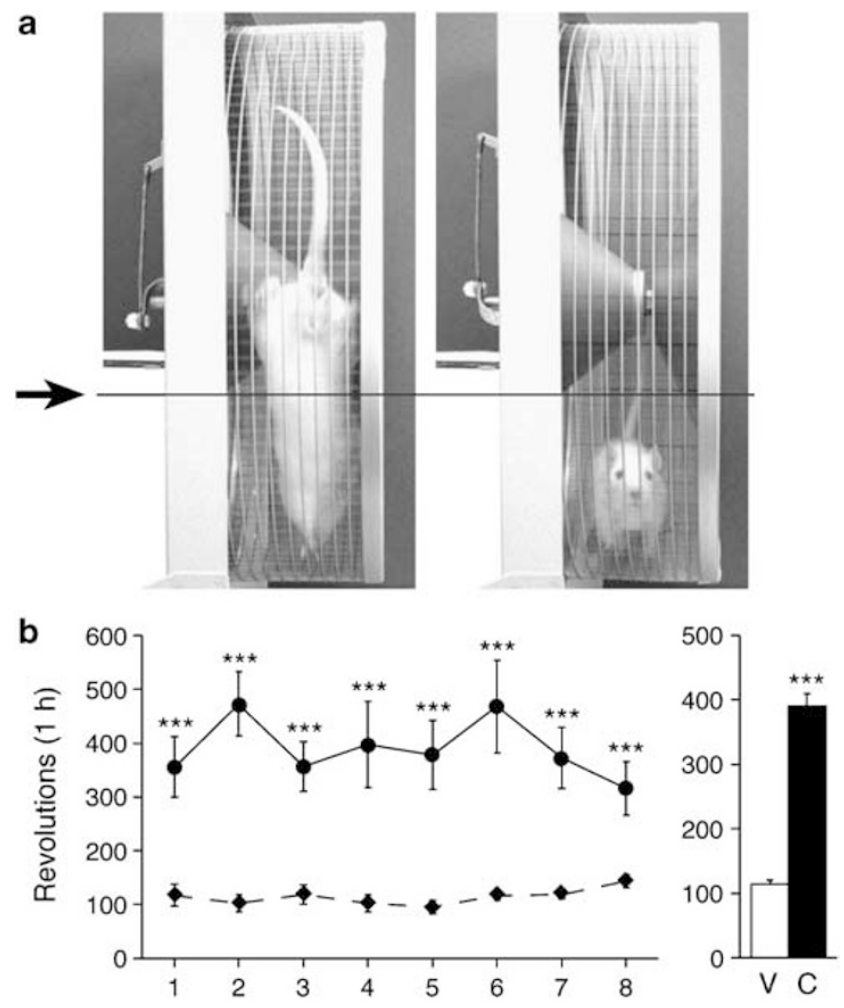

。
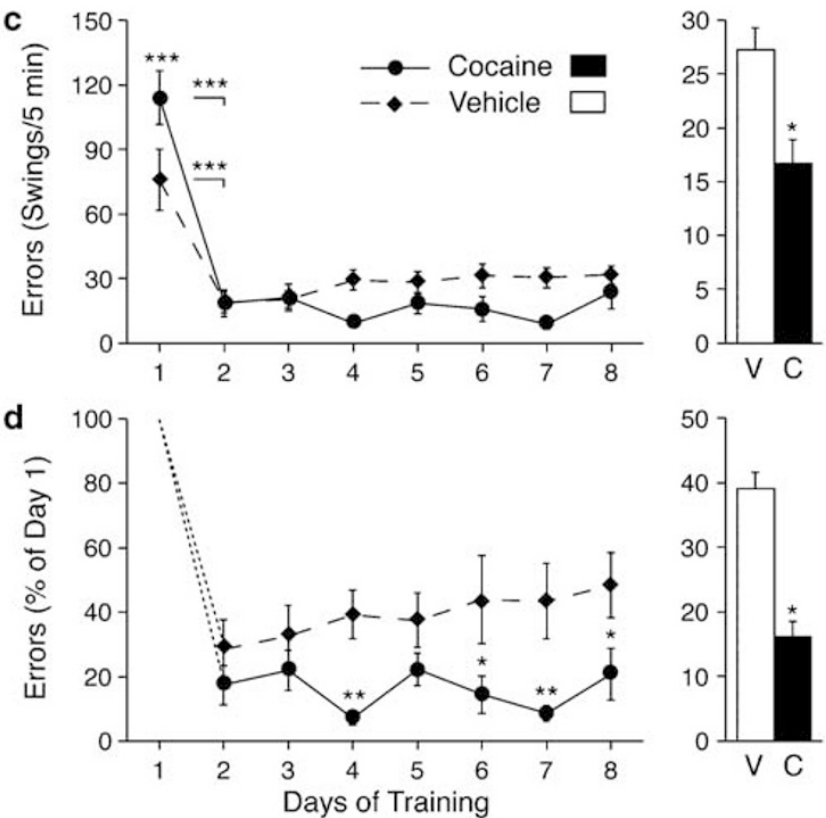

Figure I Motor-skill learning during running-wheel training. Rats learn to adjust their running such as to remain at the bottom of the moving wheel. (a) Video stills depict a rat at the beginning of the training while committing a running error ('swing') (left), and a rat running at the bottom after some practicing (right). Running errors were assessed by counting interruptions of an arbitrary line (arrow) by the rat's body (minus tail). (b) The total number of full wheel revolutions (mean \pm SEM) per I-h session on training days I-8 (left) and the average number of revolutions across sessions I-8 (right) are shown for rats treated with vehicle $(V)$ or cocaine $(25 \mathrm{mg} / \mathrm{kg}, \mathrm{C})$. (c) The number of running errors (swings) during the first 5-min periods of training sessions $1-8$ (left) and the average number of errors in these periods across sessions 2-8 (right) are given for cocaine- and vehicle-treated rats. (d) The number of running errors during the first 5-min periods, expressed as percentage of the error score on day I, for sessions 2-8 (left) and the average relative error score for these sessions (right) are shown for these two groups. $* * * *<<0.001$, ** $P<0.01, * P<0.05$ vs $V$, or as indicated. to bregma; Paxinos and Watson, 1998), a mid-striatal $(+0.4)$, and two caudal, postcommissural striatal levels (caudal $1,-0.8$, and caudal $2,-1.1$ ), in a total of 26 sampling areas (sectors) that were defined mostly based on their predominant cortical inputs (see Willuhn et al, 2003). Of these, 23 sectors represented the caudate-putamen and three the nucleus accumbens (medial shell, lateral shell, core) (Figure 3b). Levels of gene expression were measured on film autoradiograms with a Macintoshbased image analysis system (NIH Image, Wayne Rasband, NIMH). The films were captured using a light table (Northern Light; Imaging Research, St Catharines, Ontario, Canada) and a Sony CCD camera (Imaging Research). The 'mean density' value of a region of interest was measured by placing a template over the captured image. Mean density values of corresponding sectors in the two hemispheres were averaged after correcting for background by subtracting the mean density measured over white matter (corpus callosum). For illustrations of topographies, the difference in gene expression between 'running' and 'locked' groups in a given striatal sector was expressed as the percentage of the maximal difference observed (\% of max.). The illustrations of film autoradiograms displayed in Figure 2 are computer-generated. Maximal hybridization signal is black.

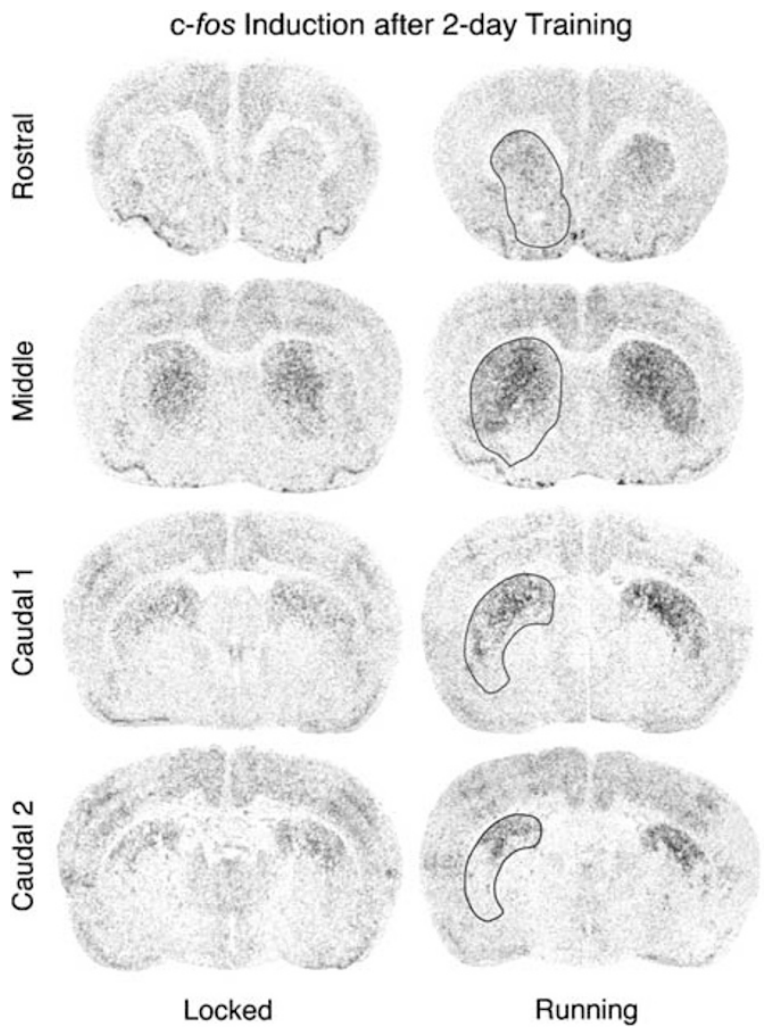

Figure 2 Effects of running-wheel training on c-fos inducibility in the striatum. Illustrations of film autoradiograms show c-fos induction in coronal sections from the rostral, middle, and caudal striatum in rats that received a cocaine challenge injection $(25 \mathrm{mg} / \mathrm{kg}) 24 \mathrm{~h}$ after the 2-day training on a locked wheel (left) or a running wheel (right) under the influence of cocaine $(25 \mathrm{mg} / \mathrm{kg})$. Running-wheel training increased c-fos inducibility in the striatum. The left striatum is outlined on the right panels. 


\section{Statistical Analysis}

The three time points (1-day, 2-day, 8-day training) were investigated in independent studies for technical reasons (eg the limited number of experimental groups that could be processed simultaneously). For each time point, treatment effects were determined with two-factor ANOVAs (factors 'training' (running vs locked) and 'drug' (cocaine $v s$ vehicle)), followed by Newman-Keuls post hoc tests (Statistica, StatSoft, Tulsa, OK). This experimental design precluded a statistical comparison of the effects at these three time points (factor 'time'), and conclusions were thus based on whether or not treatment effects were present at individual time points.

\section{RESULTS}

\section{Running-Wheel Learning}

On the running wheel, rats given cocaine showed mostly running and galloping, sometimes for extended time periods. When rats stopped, they displayed sniffing and some rearing. On the locked wheel, rats under the influence of cocaine showed sniffing, rearing, and local movements. The behavior on the running wheel was analyzed in more details in the 8-day training study (Figure 1). Cocainetreated rats showed 2-4 times more running (full wheel revolutions) than vehicle controls (RC/C vs RV/V) throughout the eight training sessions (significant main effect for drug treatment, days 1-8, $P<0.001$; two-factor ANOVA, independent factor 'drug', repeated factor 'sessions') (Figure $1 \mathrm{~b}$ ). Rats will voluntarily run on a wheel given the opportunity (see eg Sherwin (1998) for a review); however, coordinated wheel running has to be learned. Our video analysis demonstrated that, at the beginning of the training, rats had difficulty running with an appropriate speed to remain at the bottom of the wheel. Often, the rat was either too fast or too slow relative to the speed of the wheel. Consequently, the momentum of the wheel caused the rat to 'swing' (Figure 1a). We assessed the number of interruptions, by the rat's body minus tail, of a line marked on the video monitor (at approximately $1 / 3$ of the wheel diameter above the bottom; Figure 1a) as an index of performance error. The number of errors (swings) was maximal at the beginning of each session. For both rats under the influence of cocaine or vehicle, the error number dropped to a stable, low level within the first 10-15 min of the session (data not shown), as the rats learned to adjust and stabilize their running (within-session learning).

Figure 1c shows the running errors in the first 5-min period of the eight training sessions, for cocaine- and vehicle-treated rats. On day 1 , rats under the influence of cocaine produced approximately 50\% more errors than vehicle-treated rats $(P<0.001)$ (but also ran more). On day 2 , the running performance was significantly improved in both groups ( $v$ s day $1, P<0.001$; between-session learning). However, relative to their initial error score, cocaine-treated rats improved more and continued to show less errors than vehicle-treated rats through the 8-day training period (significant main effect for drug treatment, days 2-8, $P<0.05$; Figure $1 \mathrm{~d}$ ), despite running more. This effect was most pronounced from training day 4 onwards. More improved running in cocaine-treated rats was also seen when the number of swings was normalized to correct for different amounts of running (average number of swings/ revolution (first $5 \mathrm{~min}$ ) across days $2-8, \mathrm{RC} / \mathrm{C} v s \mathrm{RV} / \mathrm{V}$, $0.41 \pm 0.05$ vs $0.84 \pm 0.03$ (mean $\pm \mathrm{SEM}), P<0.01)$. These findings indicate that cocaine improved this motor learning.

\section{Training Effects on c-fos Induction}

Enduring cellular changes produced by the behavioral training were assessed 1 day after the training. Animals received an injection of cocaine or vehicle, were placed in activity monitors, and were killed $30 \mathrm{~min}$ later. In order to minimize possible effects on gene expression by environmental stimuli associated with the training/drug preexposure (Brown et al, 1992; Neisewander et al, 2000), the challenge test was performed in a different room. Thus, the differentially trained groups were tested under physically identical, neutral conditions.

For vehicle-treated rats, no significant differences in c-fos mRNA levels between running wheel- and locked wheeltrained groups (RV/V vs LV/V) were found in any of the 26 striatal sectors, after 1, 2, or 8 days of training (Figure 3a). The only exception was a slightly lower level $(P<0.05)$ in 'runners' in the ventral sector on the $\mathrm{C} 1$ level after the 2-day training (not shown).

The topography of c-fos induction by the cocaine challenge injection was similar to acute c-fos induction, as described before (Willuhn et al, 2003). Thus, c-fos expression increased maximally in the dorsal sectors on all rostrocaudal levels (Figures 2 and 3), followed by the other sensorimotor sectors (dorsolateral, ventrolateral) and the central and medial sectors. Cocaine effects were minimal or absent in ventral sectors, including the sectors of the nucleus accumbens (Figure 2). Overall, c-fos induction diminished to some degree with longer training duration (8 days; Figure 3a), consistent with blunted gene responses after repeated cocaine treatment (see Willuhn et al, 2003). Our statistical analysis showed that cocaine produced significantly increased c-fos mRNA levels (C/C vs V/V) in 20 ('running') and 18 ('locked') of the 26 striatal sectors after the 1-day training, in 22/18 sectors after the 2-day training, and in 14/14 sectors following the 8-day training (data for only the dorsal sectors are shown; Figure 3a).

Significant effects of the behavioral training on c-fos expression were found after short, but not long, training durations. After the 1-day training, cocaine-induced c-fos expression was significantly greater in 'running' than in 'locked' animals in six of the 26 sectors (RC/C vs LC/C; all $P<0.05)$ (Figure 3 ). Five of these sectors were on the caudal $\mathrm{C} 1$ level and one on the rostral level (Figure $3 \mathrm{~b}$ ). The training effects were maximal and most widespread after the 2-day training. At this time point, the cocaine challenge produced significantly higher c-fos mRNA levels in 'running' than in 'locked' groups in 10 of the 26 sectors (six of $10, P<0.01$ ) (Figures 2 and 3 ). Two of these sectors were on the rostral, four on the middle, three on the $\mathrm{Cl}$, and one on the C2 levels (Figure $3 \mathrm{~b}$ ). Eight were sensorimotor (dorsal, dorsolateral, ventrolateral) and two were medial sectors. On each level, this differential c-fos response was maximal in the dorsal sector that receives medial agranular and sensorimotor cortical inputs, was smaller in laterally 
a
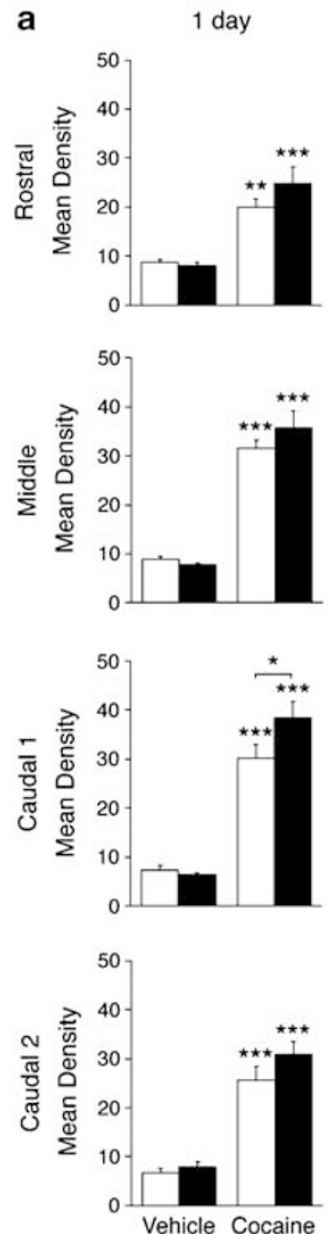
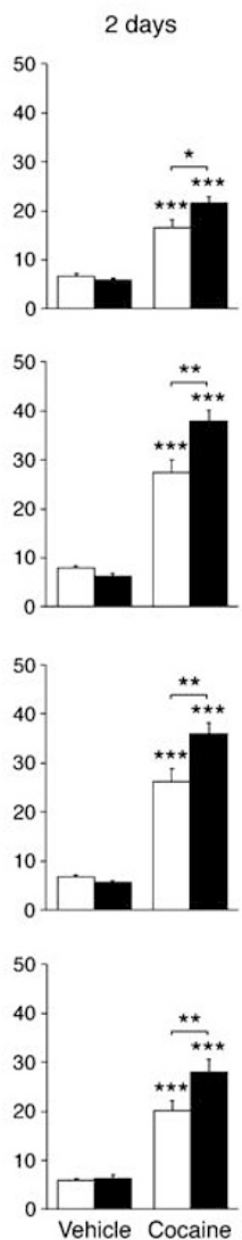

Locked c-fos Expression
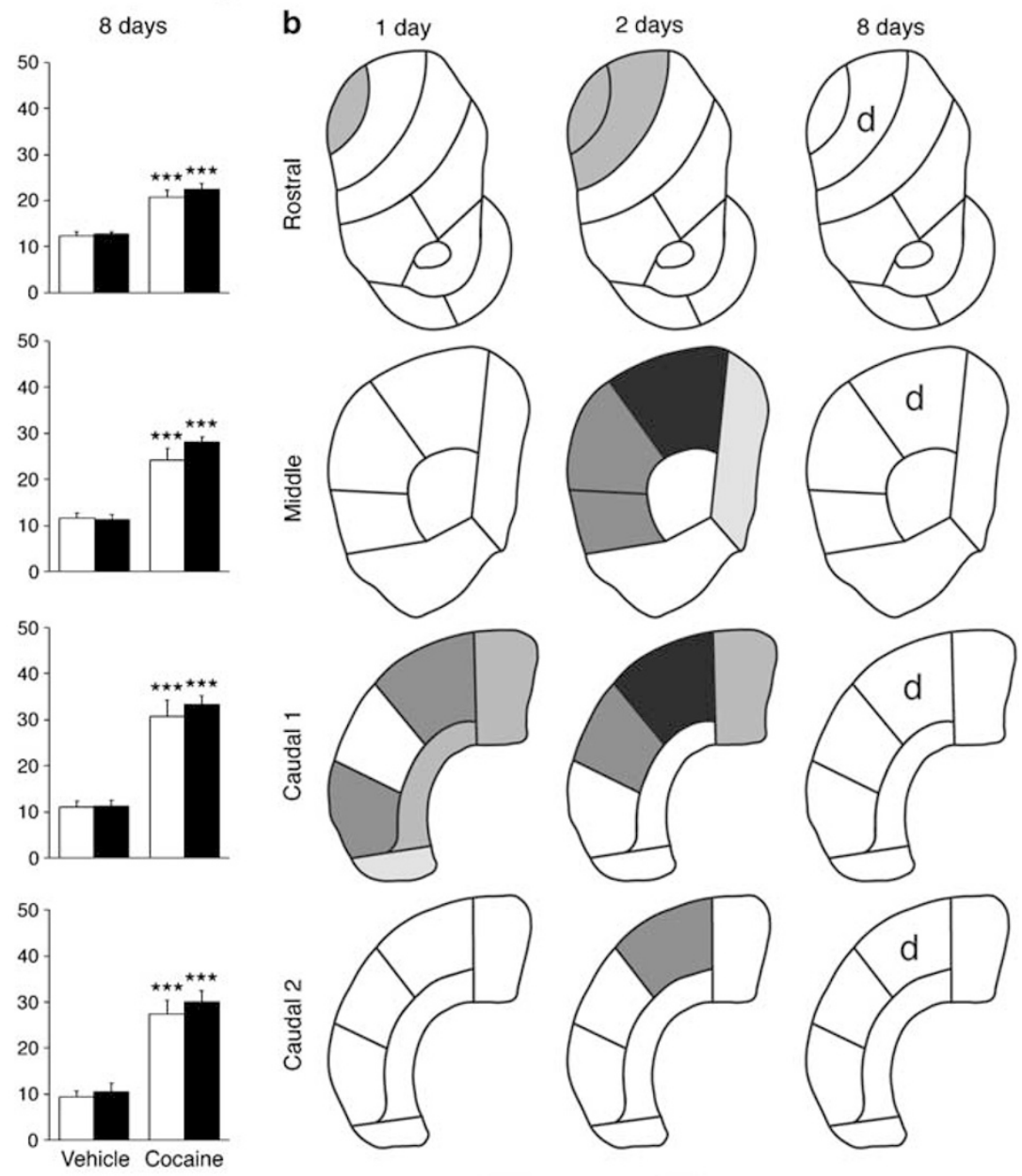

$\%$ of Max.

$P>0.05$

Figure 3 Effects of running-wheel training on c-fos expression in the striatum. (a) Mean density values (mean +SEM, arbitrary units) measured in the dorsal sector of sections from the rostral, middle, and caudal striatum are shown for rats that received a vehicle or cocaine $(25 \mathrm{mg} / \mathrm{kg})$ injection $24 \mathrm{~h}$ after the I-day, 2-day, or 8-day training on a locked wheel or a running wheel under the influence of vehicle or cocaine, respectively. (b) Maps depict the striatal sectors with statistically significant training-induced differences $(P<0.05)$ in c-fos induction after the I-day, 2-day, and 8-day training under the influence of cocaine. Differences in mean density values between running wheel- and locked wheel-trained groups are expressed as the percentage of the maximal difference (\% of max.) observed and are coded as indicated. Increased c-fos inducibility after the running-wheel training was predominantly found in the sensorimotor striatum, with maximal increases in dorsal sectors (d). This effect peaked after the 2-day training. $* * * * P<0.00$ I, *** $P<0.0$ I, *P $<0.05$ vs vehicle, or as indicated.

adjacent sensorimotor sectors, and was weakest in medial sectors (receiving input from the anterior cingulate cortex; see Willuhn et al, 2003).

In contrast, after the 8-day training, no statistically significant differences in c-fos induction between 'running' and 'locked' groups were found in any of the striatal sectors (Figure 3), although tendencies for higher expression in 'runners' were still present in some of the sensorimotor sectors.

Two additional vehicle control groups were trained for 8 days (running vs locked) and received a cocaine challenge injection 1 day later (acute cocaine, RV/C vs LV/C). These two groups did not differ in c-fos induction in any of the 26 sectors, with one exception (rostral, dorsomedial; $P<0.05$; data not shown), similar to our previous findings after the 4-day training (Willuhn et al, 2003).

\section{Training Effects on Substance $P$ and Enkephalin Expression}

The neuropeptides substance $\mathrm{P}$ and enkephalin are segregated between neurons of the two striatal output pathways and thus serve as markers for these pathways. Neurons that project to the entopeduncular nucleus and/or substantia nigra (direct pathway) mainly express substance $\mathrm{P}$, whereas neurons that project to the globus pallidus (indirect pathway) contain enkephalin (Gerfen and Wilson, 1996). We investigated whether these output pathway markers were differentially affected by the behavioral training.

In animals trained after a vehicle injection (RV/V $v s \mathrm{LV} /$ $\mathrm{V})$, substance $\mathrm{P}$ expression was not affected by the differential training in any of the sectors, after the 1-, 2-, 
or 8-day training (Figure 4, for dorsal effects), with the one exception of borderline higher expression in 'runners' $(P<0.05)$ in the ventrolateral sector on the $\mathrm{C} 2$ level after the 1-day training (data not shown).

Cocaine-induced increases in substance $\mathrm{P}$ expression were mostly found after the 1- and 2-day training and were more robust in 'runners' (Figure 4). Following the 1-day training, significantly higher substance $\mathrm{P}$ mRNA levels in cocaine-treated running wheel-trained rats ( $\mathrm{RC} / \mathrm{C} v s \mathrm{RV} / \mathrm{V})$ were seen in a total of 16 sectors across all rostrocaudal levels (rostral, five; middle, four; $\mathrm{C} 1$, three; $\mathrm{C} 2$, four) (locked wheel-trained, LC/C vs LV/V, six sectors). After the 2-day training, 'runners' displayed cocaine-induced substance $\mathrm{P}$ expression in 12 sectors ('locked', one), whereas after the 8day training, substance $\mathrm{P}$ mRNA levels in 'runners' were significantly enhanced only in 6 sectors, including three dorsal sectors ('locked', five) (Figure 4).

Significant differences in cocaine-induced substance $\mathrm{P}$ expression between 'running' and 'locked' groups (RC/C vs
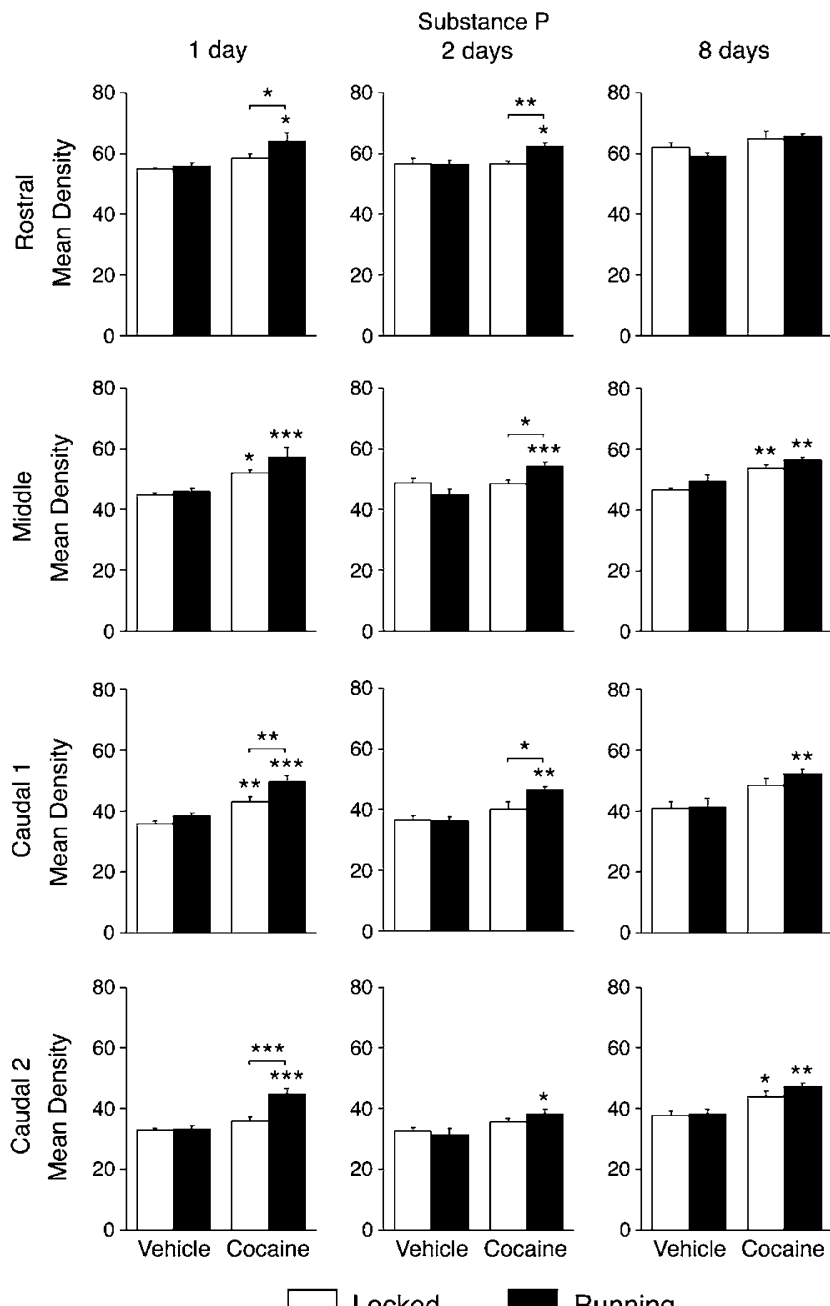

Locked

Running

Figure 4 Effects of running-wheel training on substance $P$ expression in the striatum. Mean density values (mean \pm SEM) measured in the dorsal sector of rostral, middle, and caudal striatal sections are given for rats that received vehicle or cocaine $(25 \mathrm{mg} / \mathrm{kg}) 24 \mathrm{~h}$ after the I-day, 2-day, or 8-day training on a locked wheel or a running wheel. ${ }^{*} * * P<0.00$ I, $* * P<0.0$ I, $* P<0.05$ vs vehicle, or as indicated.
LC/C) were found after the 1- and 2-day training, but not after the 8-day training (one exception) (Figures 4 and 5a). After the 1-day training, 'runners' displayed higher substance $\mathrm{P}$ mRNA levels in 12 sectors, four on rostral, three on C1, and five on C2 levels. Following the 2-day training, 'running' rats showed higher expression in nine sectors, three on rostral, three on middle, and three on $\mathrm{C} 1$ levels.

In contrast to substance $\mathrm{P}$, effects on enkephalin expression were minor (Figure $5 b$ ). 'Runners' trained after a vehicle injection (RV/V) displayed significantly higher enkephalin mRNA levels than 'locked' animals (LV/V) in three rostral sectors (medial, dorsomedial, dorsal; $P<0.01$ ) after the 2-day training (not shown). Only borderline effects $(P<0.05)$ of cocaine on enkephalin expression were seen for 'running' (RC/C vs RV/V; three sectors total) and 'locked' groups (one sector), across all three training durations (not shown). The only training effect in cocaine-treated rats (RC/ $\mathrm{C}$ vs LC/C) was a slightly lower enkephalin mRNA level $(P<0.05)$ in 'runners' in the ventral sector on $\mathrm{C} 1$ after the 1 day training (Figure $5 b$ ).

\section{Effects on Dynorphin Expression}

Repeated treatment with psychostimulants such as cocaine produces increased dynorphin expression in the striatum (see Willuhn et al, 2003), a neuroadaptation implicated in behavioral and other changes in psychostimulant addiction (Hyman and Nestler, 1996; Nestler, 2001). Our previous study showed increased dynorphin expression after the 4-day repeated training under the influence of cocaine ( $v s$ vehicle), but this effect was independent of the training conditions (Willuhn et al, 2003). We thus examined whether prolonged differential behavioral training (8 days) would produce differential effects on dynorphin expression (Werme et al, 2000). This was not the case. The 8-day training under the influence of cocaine produced increased dynorphin expression $(P<0.01)$ in five striatal sectors, most prominently in the dorsal sectors on the middle and caudal $(\mathrm{C} 1, \mathrm{C} 2)$ striatal levels (Figure 6), as seen before (Willuhn et al, 2003). However, these effects did not differ between $\mathrm{RC} / \mathrm{C}$ and LC/C animals, confirming our previous findings (Willuhn et al, 2003).

\section{Training Effects on Challenge-Induced Behavior}

Behavioral effects of the training/drug challenge were determined in activity monitors during $30 \mathrm{~min}$ before the rats were killed. Assessed were ambulation distance and local repetitive movements ('stereotypy' counts), as in our earlier study (Willuhn et al, 2003). No difference in ambulation or stereotypy counts between 'running' and 'locked' groups treated with vehicle (RV/V vs LV/V) was found after any training duration (Figure 7). Cocainechallenged 'running' and 'locked' groups displayed significantly more ambulation than their respective vehicle controls (C/C vs V/V) (Figure 7a). This effect was more robust after the 1 -day and 2 -day training $(P<0.001)$ than after the 8 -day training $(P<0.01)$. In contrast, stereotypy counts increased with longer training duration (ie with more repeated cocaine treatments) and faster so in 'locked' 


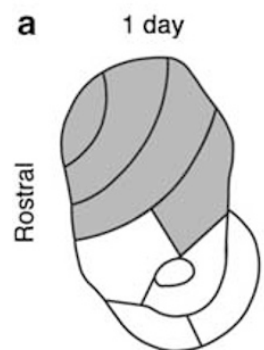

\section{Substance $P$}
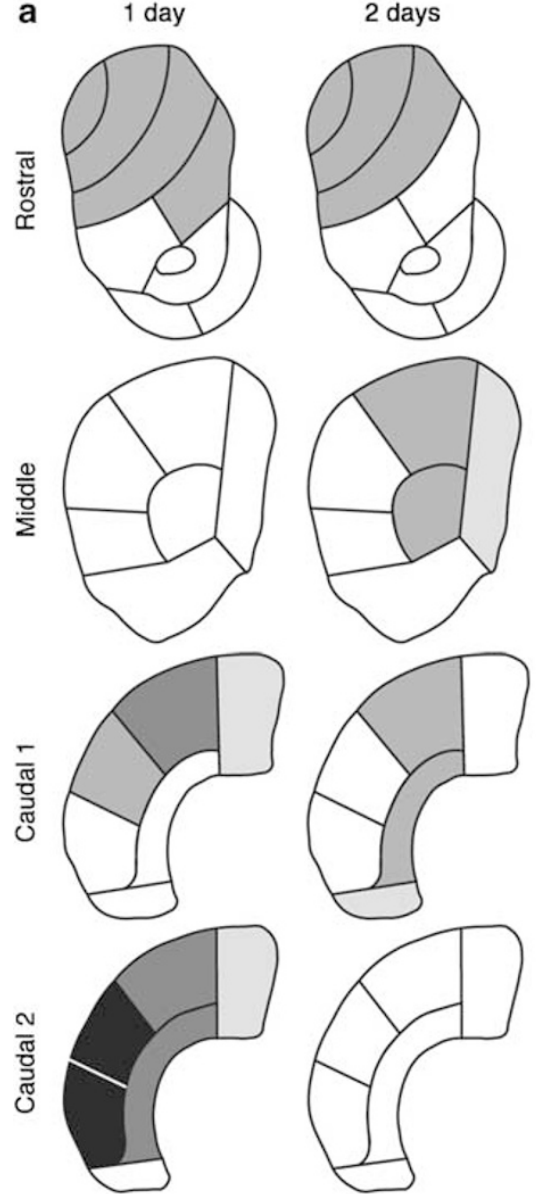

$\%$ of Max
$100-80 \%$ $80-60 \%$
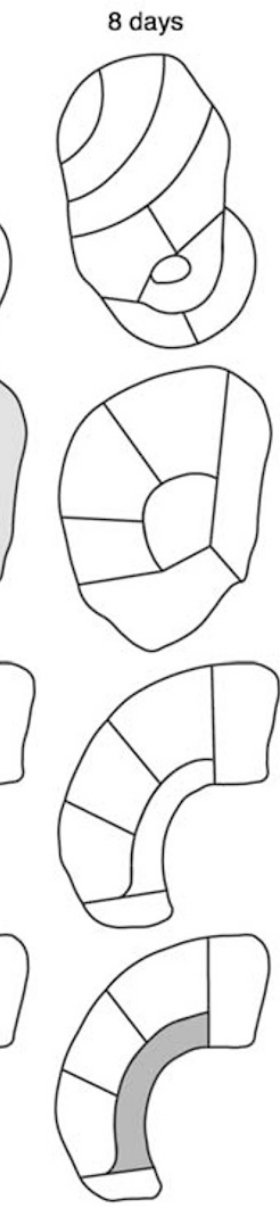

b
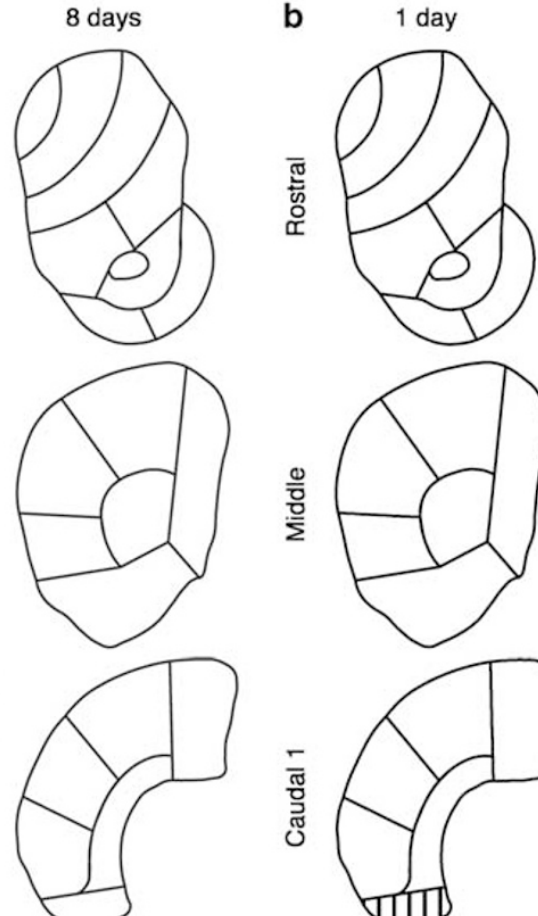

$60-40 \%$

$40-20 \%$
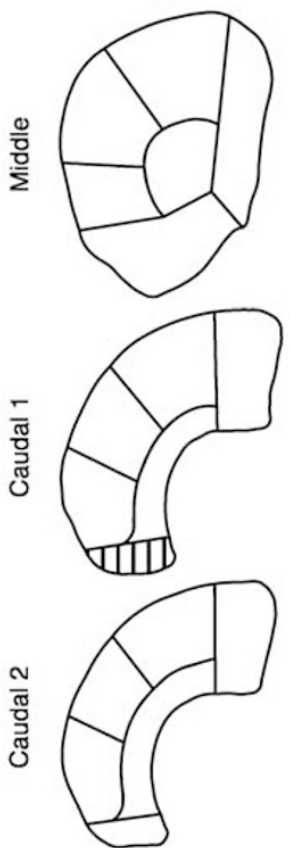

Enkephalin

2 days
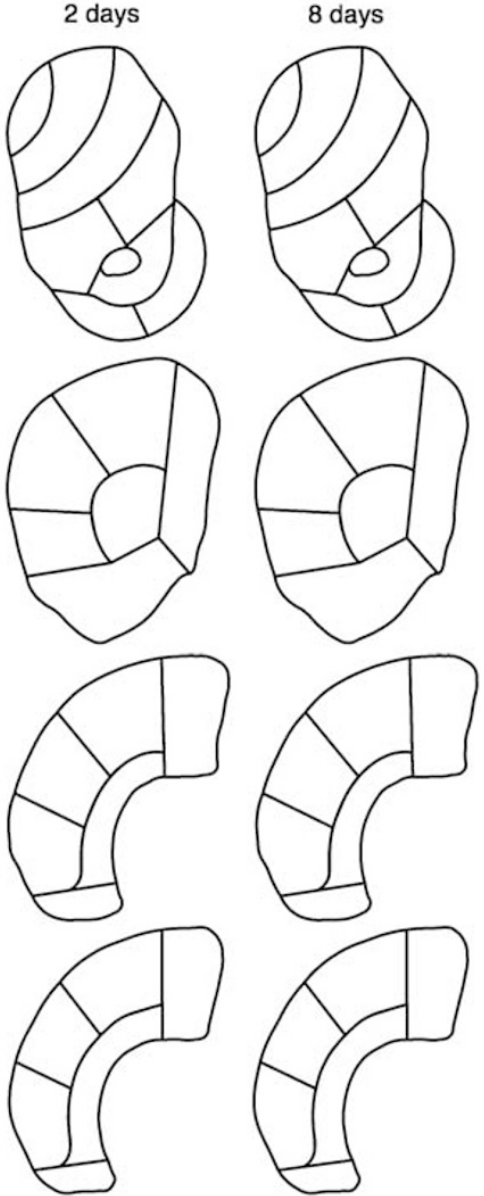

Figure 5 Regional distribution of training effects on substance $P(a)$ and enkephalin (b) expression in the striatum. The maps depict training-induced differences $(P<0.05)$ in gene expression after the 1 -day, 2-day, and 8-day training under the influence of cocaine. For substance $P$, differences in mean density values (running wheel- minus locked wheel-trained groups) are expressed as the percentage of the maximal difference (\% of max.) observed and are coded as indicated. 'Runners' showed increased substance P induction predominantly at the beginning of the training. For enkephalin expression, only one sector with a borderline significant effect (decrease) was found in 'runners' (hatched).

groups (Figure 7b). After the 1-day training, only 'locked' rats showed significantly increased stereotypy counts (LC/C vs LV/V; $P<0.05)$. Following the 2-day training, both 'locked' $(P<0.001)$ and 'running' $(P<0.05)$ groups displayed more stereotypies, as they did after the 8-day training (both $P<0.001$ ). Overall, stereotypy counts were negatively correlated with ambulation counts after the 1-day (all $\mathrm{C} / \mathrm{C}$ animals pooled; $r=-0.68, P<0.01$ ), the 2-day $(r=-0.82, P<0.001)$, and the 8 -day training $(r=-0.65$, $P<0.05)$.

Significant training effects (RC/C $v s \mathrm{LC} / \mathrm{C})$ were seen for ambulation and stereotypy counts after the short, but not long, training durations. The ambulation counts were significantly higher in running wheel-trained than in locked wheel-trained groups $(P<0.05)$ after the 1 -day training, whereas the stereotypy counts were lower in 'running' than 'locked' groups $(P<0.01)$ after the 2-day training (Figure 7). No other behavioral differences were found.

\section{Relationship between Challenge-Induced Behavior and Gene Expression?}

Earlier findings indicated a possible relationship between psychostimulant-induced behavioral activation and striatal gene induction. For example, the time course of methylphenidate-induced substance $\mathrm{P}$ expression in the caudal sensorimotor striatum, but not in the rostral striatum, paralleled that of behavioral activation by this drug (see Yano and Steiner, 2005b). This raises the possibility that sensorimotor feedback produced by the behavioral activation could contribute to the observed gene regulation effects. In the present study, the differentially trained groups, $\mathrm{RC} / \mathrm{C}$ and LC/C, displayed some differential behavioral activation by the cocaine challenge after the 1- and 2-day training (Figure 7). We thus investigated, by a correlation analysis, whether the differences in c-fos and substance P expression after the differential training (see above) could be related to 

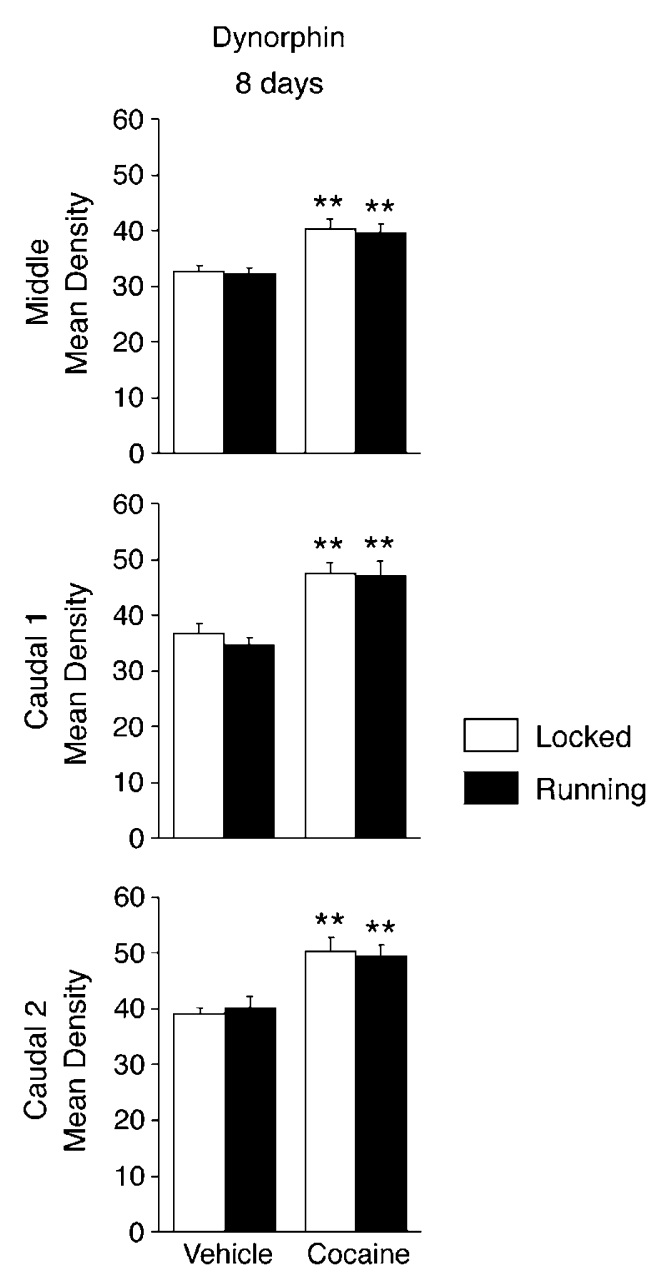

Figure 6 Lack of effects of running-wheel training on dynorphin expression in the striatum. Mean density values (mean \pm SEM) measured in the dorsal sector of middle and caudal striatal sections are shown for rats that received vehicle or cocaine $24 \mathrm{~h}$ after the 8-day training on a locked wheel or a running wheel. No training-induced changes were found. *** $P<0.01$ vs vehicle.

these behavioral differences. The increase in ambulation (over averaged vehicle controls) was correlated with the increase in c-fos or substance $\mathrm{P}$ expression for individual animals of groups RC/C and LC/C (pooled).

Our results (Table 1) show that, after the 1-day training, cocaine challenge-induced ambulation was positively correlated with c-fos induction in 14 of the 26 sectors $(r=0.58$ $0.77, P<0.05)$ and with increases in substance $P$ expression in 10 sectors $(r=0.53-0.78, P<0.05)$. In contrast, after the 2 -day training, ambulation was positively correlated with c$f o s$ induction in none of the 26 sectors $(P>0.05)$ and with substance $\mathrm{P}$ expression in five sectors $(r=0.54-0.62$, $P<0.05)$. Moreover, a comparison of the distribution of sectors with significant correlations between ambulation and gene induction (Table 1) and that with training-related differential gene induction (Figures $3 \mathrm{~b}$ and $5 \mathrm{a}$ ) shows that these sectors poorly overlapped. (Stereotypy counts tended to be lower in RC/C animals ( $v s$ LC/C; Figure 7) and were thus negatively correlated with gene induction in a few sectors (c-fos: 1 day, one sector; 2 days, zero sectors; substance P: 1 day, one sector; 2 days, seven sectors) (results not shown).) Therefore, we conclude that challenge-

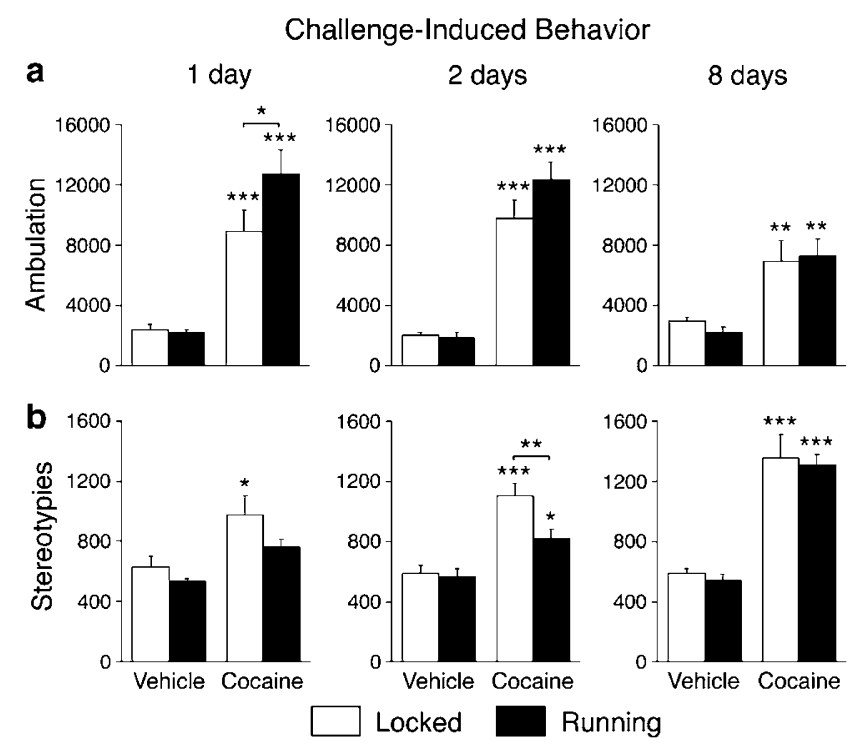

Figure 7 Challenge-induced behavioral effects after the 1-day, 2-day, and 8-day wheel training. (a) The number (mean \pm SEM) of ambulation counts in the activity monitor during the 30-min test session is given for rats that received locked-wheel or running-wheel training under the influence of vehicle or cocaine, and were challenged with vehicle or cocaine, respectively, $24 \mathrm{~h}$ after the training ended. (b) The number of local repetitive movements ('stereotypy' counts) during the test session for these groups is depicted. **** $P<0.001$, **P $<0.01$, $* P<0.05$ vs vehicle, or as indicated.

induced sensorimotor feedback was not a major contributor to the differential induction of c-fos and substance $\mathrm{P}$, especially not to the enhanced c-fos response in 'runners' after the 2-day training (Figure $3 \mathrm{~b}$ ). These findings are consistent with the lack of a relationship between challengeinduced behavioral activation and training-related differential c-fos expression observed after a 4-day training (Willuhn et al, 2003).

\section{DISCUSSION}

Psychostimulant-induced changes in gene regulation are particularly pronounced in cortico-basal ganglia circuits through the sensorimotor striatum. Our previous study first showed that wheel training interacts with cocaine to affect gene regulation in the sensorimotor striatum (Willuhn et al, 2003). Rats that trained under the influence of cocaine for 4 days displayed more robust c-fos induction than cocainetreated nonrunning controls when given a cocaine challenge on day 5. Cocaine action during the training was required for this enhanced cellular responsiveness to occur (Willuhn et al, 2003). In the present study, we investigated whether these molecular changes were produced by repeated exercising or were associated with the beginning of the training when rats learn to run on the wheel, by comparing the effects of extended running (8 days) with those occurring during the first 2 days. Our results demonstrate that training-related enhanced $\mathrm{c}$-fos inducibility was restricted to the beginning of the wheel training and predominantly occurred in the sensorimotor striatum. Similar effects were found for substance $P$, but not enkephalin, expression. Our findings also show that these 
Table I Correlations between Cocaine Challenge-Induced Ambulation and Gene Expression in the Striatum

\begin{tabular}{|c|c|c|c|c|c|c|}
\hline & \multicolumn{3}{|c|}{$c-f o s$} & \multicolumn{3}{|c|}{ Substance $\mathbf{P}$} \\
\hline & I day & 2 days & 8 days & I day & 2 days & 8 days \\
\hline \multicolumn{7}{|l|}{ Rostral } \\
\hline Medial & 0.50 & 0.14 & 0.38 & 0.44 & 0.39 & 0.04 \\
\hline Dorsomedial & $0.74 * *$ & 0.23 & 0.13 & 0.35 & 0.16 & -0.08 \\
\hline Dorsal & $0.65 *$ & 0.25 & -0.10 & 0.51 & 0.22 & -0.04 \\
\hline Dorsolateral & $0.7 \mid * * *$ & 0.28 & -0.20 & $0.67 *$ & 0.09 & -0.43 \\
\hline Ventral & 0.32 & 0.12 & -0.48 & 0.02 & -0.44 & 0.31 \\
\hline Nacc core & -0.13 & -0.12 & -0.28 & 0.09 & 0.26 & 0.32 \\
\hline Medial shell & 0.17 & -0.09 & -0.17 & -0.31 & 0.31 & 0.47 \\
\hline Lateral shell & 0.08 & -0.27 & -0.08 & -0.10 & -0.01 & 0.46 \\
\hline \multicolumn{7}{|l|}{ Middle } \\
\hline Medial & 0.36 & 0.26 & 0.08 & 0.11 & $0.59 *$ & 0.30 \\
\hline Dorsal & 0.77 *** & 0.38 & -0.12 & $0.57 *$ & $0.56 *$ & -0.11 \\
\hline Dorsolateral & $0.72 * *$ & 0.21 & -0.55 & 0.51 & 0.36 & 0.25 \\
\hline Ventrolateral & $0.70 * *$ & 0.18 & -0.60 & $0.65 *$ & 0.24 & 0.18 \\
\hline Ventral & -0.03 & -0.03 & $-0.61 *$ & 0.24 & -0.21 & 0.08 \\
\hline Central & $0.72 * *$ & 0.49 & -0.45 & $0.62 *$ & 0.45 & -0.11 \\
\hline \multicolumn{7}{|l|}{ Caudal I } \\
\hline Medial & $0.70 * *$ & 0.20 & 0.05 & $0.78^{* * *}$ & 0.41 & -0.18 \\
\hline Dorsal & $0.73 * *$ & 0.51 & -0.21 & $0.64 *$ & $0.62 *$ & -0.10 \\
\hline Dorsolateral & $0.60 *$ & 0.15 & -0.53 & 0.12 & $0.59 *$ & -0.36 \\
\hline Ventrolateral & $0.68 * *$ & 0.12 & -0.25 & -0.11 & 0.08 & 0.00 \\
\hline Ventral & 0.52 & 0.24 & -0.06 & $0.53^{*}$ & -0.06 & 0.41 \\
\hline Central & $0.7 \mid$ I** & 0.19 & -0.39 & $0.57 *$ & 0.05 & -0.17 \\
\hline \multicolumn{7}{|l|}{ Caudal 2} \\
\hline Medial & $0.60 *$ & 0.19 & -0.21 & $0.58 *$ & $0.54 *$ & -0.05 \\
\hline Dorsal & $0.58 *$ & 0.39 & -0.31 & 0.78 *** & 0.43 & -0.25 \\
\hline Dorsolateral & 0.41 & -0.01 & -0.57 & 0.51 & 0.18 & -0.17 \\
\hline Ventrolateral & 0.41 & -0.37 & -0.42 & 0.02 & -0.07 & 0.28 \\
\hline Ventral & -0.09 & $-0.64 *$ & -0.11 & -0.36 & -0.20 & 0.31 \\
\hline Central & 0.48 & 0.08 & -0.52 & 0.35 & 0.28 & 0.18 \\
\hline
\end{tabular}

Correlation coefficients $(r)$ for correlations between increases in ambulation and c-fos (left) or substance P mRNA levels (right) in 26 striatal sectors are shown for rats that received a cocaine challenge $(25 \mathrm{mg} / \mathrm{kg}) 24 \mathrm{~h}$ after the 1 -, 2- or 8 day wheel training (RC/C and LC/C groups pooled). Nacc, nucleus accumbens. ** $P<0.0$ l, * $P<0.05$.

training-induced molecular changes were paralleled by improvement in wheel running proficiency, which was greater in rats that trained under the influence of cocaine. Therefore, these molecular effects may reflect changes in gene expression related to learning to run on the wheel.

\section{Running Training and Gene Regulation in the Striatum}

Previous work demonstrated that running is associated with neuronal changes in striatal circuits. For example, acute in vivo microdialysis studies found that treadmill running increases dopamine and glutamate release in the dorsal and ventral striatum (Hattori et al, 1994; Wilson and Marsden, 1995; Meeusen et al, 1997). Only a few studies investigated the effects of running on gene expression in the striatum. These showed that the expression of c-fos, substance $\mathrm{P}$, and enkephalin was increased in parts of the dorsal striatum immediately after treadmill running (Liste et al, 1997, 1999). These effects were dependent on dopamine (D1) and glutamate (NMDA)/cortical inputs. Prolonged voluntary wheel running was also found to increase dynorphin mRNA levels in the medial striatum (Werme et al, 2000).

While the above studies demonstrate that running can alter striatal gene expression, the running paradigms used differed in important aspects from the running training in our studies. Liste et al $(1997,1999)$ employed running on a straight motorized treadmill (fixed speed), which was practiced first (seven daily sessions) and was motivated by foot shocks. The wheel running study by Werme et al (2000) involved 30 days of unlimited access to the wheel from the home cage. In contrast, our effects were found after $1 \mathrm{~h}$ of voluntary wheel running on 1-4, but not 8 , days of training (present study; Willuhn et al, 2003). Thus, the above studies assessed molecular changes after running in well-trained rats, whereas our present and previous findings revealed molecular changes that occurred during the early phase of the training when rats learn to run on the wheel.

More similar to our studies, Kitsukawa et al (2002, 2004) recently assessed striatal gene regulation associated with learning to run on a wheel. They investigated striatal c-fos expression during learning of new stepping patterns (forced gait change on a motorized wheel in well-trained mice). Results showed that c-fos expression was enhanced in the dorsolateral striatum during the relearning phase (effect maximal on but not limited to the first day of gait change; Kitsukawa et al, 2002). However, similar to the above studies (Liste et al, 1997, 1999), this effect was obtained immediately after wheel performance. In contrast, our finding of increased c-fos inducibility after running-wheel training under the influence of cocaine was obtained $24 \mathrm{~h}$ after the training. Thus, the molecular changes found in our studies reflect persistent neuronal changes produced by the training.

\section{Evidence for Molecular Changes in the Direct Pathway Associated with Wheel Training}

Which striatal output neurons are affected by wheel training? Projection neurons of the direct striatal output pathway express substance $P$ and the D1 dopamine receptor, whereas neurons of the indirect pathway (striatopallidal neurons) contain enkephalin and mostly D2 receptors (Gerfen and Wilson, 1996). We did not determine which of these two pathways showed differential c-fos induction by the cocaine challenge after the running-wheel training. Psychostimulant-induced immediate-early gene expression is principally mediated by D1 receptors (Graybiel et al, 1990; Young et al, 1991; Cole et al, 1992; Steiner and Gerfen, 1995; Drago et al, 1996; Moratalla et al, 1996) in interaction with glutamate input (see Berke and Hyman, 2000). Moreover, double-labeling studies demonstrated that psychostimulants induce c-fos predominantly in direct 
pathway neurons (Berretta et al, 1992; Cenci et al, 1992; Johansson et al, 1994; Kosofsky et al, 1995; Badiani et al, 1999), especially with higher doses (Uslaner et al, 2003; Ferguson et al, 2004) as used here. However, recent studies showed that factors such as novelty can enhance c-fos induction by psychostimulants also in the indirect pathway (Badiani et al, 1999; Uslaner et al, 2003; Ferguson et al, 2004). In order to reduce potential confounds by situational novelty, the running-wheel training was performed in the animals' housing room, and controls were exposed to equally novel locked wheels. Nonetheless, it is conceivable that pairing cocaine with wheel running altered c-fos expression also in indirect pathway neurons. Future studies will have to clarify which neurons showed altered c-fos induction.

In the present study, we used substance $P$ and enkephalin as markers for training effects in these two pathways. Our results show increased cocaine-induced substance $\mathrm{P}$ expression $24 \mathrm{~h}$ after the 1- and 2-day wheel training. These substance $\mathrm{P}$ effects were also most pronounced in the sensorimotor striatum. Time course and regional distribution of changes in substance $\mathrm{P}$ expression, however, did not completely match those of the c-fos effects (eg greater c-fos but not substance $\mathrm{P}$ changes after 2-day vs 1-day training). These results are consistent with previous findings (eg Drago et al, 1996; Yano and Steiner, 2005b), indicating that these two genes are at least in part differentially regulated. Nevertheless, these substance $P$ effects indicate trainingrelated molecular changes in direct pathway neurons, in agreement with the previous finding of preferential c-fos induction in direct neurons during stepping pattern relearning (Kitsukawa et al, 2002).

The above changes in c-fos and substance $\mathrm{P}$ expression contrast with minimal or no training effects on enkephalin expression. Striatal enkephalin expression is readily increased by other treatments including dopamine denervation/loss of D2 receptor stimulation (eg Steiner and Gerfen, 1998), and minor increases have also been reported after various psychostimulant treatments (cf. Yano and Steiner, 2005b). While our negative results for enkephalin expression do not rule out potential other training-related changes in the indirect pathway, the above findings suggest that motor learning involves neuroplastic changes in the direct pathway.

\section{Are the Observed Changes in Gene Regulation Related to Motor Learning?}

Our present behavioral analysis shows that coordinated running on a wheel is learned. At the beginning of the training, rats were unable to run with an appropriate speed such as to remain at the bottom of the moving wheel. However, they learned to adjust their running fairly quickly; most improvement occurred during the first training sessions. Our subsequent behavioral studies confirmed that one 'wheel skill' rats learn is the ability to balance/control the wheel in order to avoid 'swinging'. Moreover, these studies also showed that a 2-day running-wheel training is sufficient to produce long-term improvement in this wheel skill; this improvement lasted for at least 4 weeks (Willuhn and Steiner, 2005b). Importantly, running during the training is critical for this learning, as the improvement
(1) was correlated with the amount of running, (2) varied with the duration of the training sessions, and (3) was absent in locked wheel-trained controls (Willuhn and Steiner, 2005b; manuscript in preparation). Together, our findings demonstrate that long-lasting motor learning occurs during the first days of the wheel training.

Our present findings show that the enhanced c-fos/ substance $\mathrm{P}$ responsiveness in the striatum was limited to the early phase of the wheel training when rats learn to run. This effect was maximal after 1-2 days of training and subsequently subsided. Thus, it is possible that these molecular changes play a role in such motor memory formation. Yet, there are a number of potential alternative explanations for this differential cellular responsiveness that cannot be ruled out based on the currently available data. For example, it could be argued that stress levels/hormonal secretions were different between running wheel- and locked wheel-trained groups. While this is conceivable, it is unclear how such 'systemic' effects alone could have produced the regionally selective molecular changes in the sensorimotor striatum. Moreover, according to previous studies, striatal regions (and midbrain dopamine neurons) display relatively minor or no c-fos induction by stressors (for reviews, see Senba and Ueyama, 1997; Kovacs, 1998; Pacak and Palkovits, 2001). Also, stress was ruled out as a major contributor to striatal c-fos induction during treadmill running (Liste et al, 1997). However, it is unclear whether stress hormones modify cocaine-induced gene expression in the striatum (Barrot et al, 2001). On the other hand, running wheel- and locked wheel-trained rats differed considerably in their motor output during the training (running vs local movements), which could have contributed to differential molecular changes independent of motor learning (Liste et al, 1997, 1999). However, our finding of a lack of differential c-fos induction after the 8-day training argues against a significant effect of motor output per se. Further studies are necessary to establish whether or not the observed training-induced gene regulation effects are neuronal correlates of motor learning.

\section{Gene Regulation Enabling Motor Memory Formation: A Hypothesis}

A role of the observed molecular changes in motor learning would be consistent with the known functions of the affected striatal regions, as the sensorimotor striatum has long been implicated in motor learning (skill, procedural, or habit learning; eg Mishkin et al, 1984; White, 1989; Graybiel, 1995; Knowlton et al, 1996; Packard and Knowlton, 2002). Wheel-skill learning presumably involves integration of multisensory inputs (eg tactile, vestibular, proprioceptive, etc.) to adapt existing motor programs and generate the appropriate motor output. It is worth noting that the most affected striatal sectors do receive such convergent multisensory inputs via the cortex (Reep et al, 2003).

Early running improvement is likely mediated by shortterm memory processes, whereas persistent wheel-skill improvement is presumably the result of long-term motor memory consolidation. Long-term memory formation is known to be dependent on protein synthesis (Davis and Squire, 1984). Indeed, changes in gene expression related to learning have been described in many models of learning 
and memory (Stork and Welzl, 1999). It is thought that proteins expressed during learning allow changes in structure and efficacy of synapses thus mediating longterm memory consolidation (eg Davis and Squire, 1984; Bailey and Kandel, 1993; Bailey et al, 1996; Moser, 1999).

What are the neuronal mechanisms underlying the increased gene responsiveness in striatal neurons as found in our studies, and how could they possibly mediate motor learning? As mentioned above, c-fos (and substance P) induction is mediated by interactions between dopamine and glutamate inputs. For example, psychostimulantinduced c-fos expression is attenuated by eliminating stimulation of striatal D1 receptors (see above) or cortical inputs (Cenci and Björklund, 1993; Vargo and Marshall, 1995). Various neuronal changes in the glutamate/dopamine afferents and/or striatal neurons described after repeated cocaine treatment (Hyman and Nestler, 1996; Kuhar and Pilotte, 1996; White and Kalivas, 1998; Wolf, 1998; Kelley, 2004) could thus have contributed to the observed enhanced training-related cocaine-induced c-fos response. However, such neuroadaptations often require longer drug treatments, which questions their involvement in early memory formation.

Acute treatments can also modify cellular responsiveness. For example, long-term potentiation (LTP) and long-term depression (LTD) induced by high-frequency stimulation are forms of synaptic plasticity that have long been considered candidate processes for learning and memory. Acute high-frequency activation of cortical inputs is well known to produce LTP or LTD at the corticostriatal synapse (Calabresi et al, 1996; Centonze et al, 2001; Reynolds and Wickens, 2002; Gerdeman et al, 2003; Mahon et al, 2004), and such effects have been implicated in altered gene induction after psychostimulant treatments (Graybiel et al, 2000). Importantly, there is evidence that, in vivo, lowfrequency stimulation can be sufficient to induce LTP (Charpier et al, 1999). Both LTP and LTD are dependent on dopamine input (Calabresi et al, 1996; Centonze et al, 2001; Reynolds and Wickens, 2002), with low dopamine levels apparently favoring LTD and high dopamine levels producing LTP at the corticostriatal synapse (Reynolds and Wickens, 2002). Notably, such LTP is blocked by D1 receptor antagonism (Kerr and Wickens, 2001; Reynolds et al, 2001; Centonze et al, 2003).

We have started to investigate, with electrophysiological approaches, whether the enhanced c-fos inducibility after running-wheel training could reflect increased efficacy in corticostriatal signaling. Our preliminary results indicate that, following a 2-day running-wheel $v s$ locked-wheel training under the influence of cocaine, striatal projection neurons in 'runners' are indeed more responsive to cortical stimulation (West et al, in preparation). This enhanced synaptic efficacy persisted for at least $24 \mathrm{~h}$ after the training. These findings are consistent with a role of potentiated corticostriatal signaling in the enhanced cellular response in striatal neurons.

We speculate that running-wheel learning/memory formation involves a cascade of neuronal events, starting with early coincident inputs in convergent sensorimotor, prefrontal/limbic, dopamine (Schultz et al, 2003), and possibly other striatal afferents that would transiently potentiate neuronal responsiveness in the striatum (LTP) which would facilitate inducibility of certain genes (Miyachi et al, 2005) by potentiated or altered activation of the necessary second messenger signaling cascades (Berke and Hyman, 2000; Hyman, 2005). The affected genes appear to include transcription factors such as c-fos and neuropeptides such as substance $\mathrm{P}$ (present and previous study (Willuhn et al, 2003)), as well as synaptic plasticity regulators such as Homer 1 (Willuhn and Steiner, 2005a). Such molecular changes may enable lasting synapse modifications/restructuring (Xiao et al, 2000; Thomas, 2002), leading to enduring rearrangements in cortico-basal ganglia circuits subserving wheel running and thus long-term wheel-skill improvement (motor memory consolidation). As mentioned above, D1 receptor stimulation is critical for several of these early cellular changes. In support of this hypothesis, our recent findings demonstrate that long-term wheel-skill improvement learned during a 2-day training is dependent on D1 receptor stimulation during the training (Willuhn and Steiner, 2005b).

\section{Gene Regulation and Motor Memory Formation: Abnormally Enhanced by Cocaine?}

In our present study, wheel-skill improvement was seen in 'runners' that trained without cocaine, and cocaine facilitated this motor learning. With our present analysis, no statistically significant effects of the training on striatal gene regulation were found when the training occurred without cocaine (after a vehicle injection) (see also Willuhn et $a l, 2003)$. The employment of a more sensitive twomarker correlation analysis (Yano and Steiner, 2005b) (c-fos vs Homer 1) did, however, reveal modest training effects on gene regulation in drug-naïve, vehicle-trained animals (Willuhn and Steiner, 2005a). Therefore, cocaine appeared to abnormally enhance (or modify) learning-associated gene regulation. In the framework of the above hypothesis, this is consistent with findings at the corticostriatal synapse indicating that increasing dorsal striatal dopamine action switches LTD to LTP (Reynolds and Wickens, 2002). Such a switch has been demonstrated after repeated methamphetamine treatment (Nishioku et al, 1999). However, a single psychostimulant exposure may be sufficient to potentiate excitatory synapses (Ungless et al, 2001; Saal et al, 2003; Kauer, 2004). Such drug-induced neuronal changes may result in abnormally robust/persistent synaptic modifications and motor memory.

\section{CONCLUSIONS}

Our results show that motor learning is accompanied by changes in gene regulation in cortico-basal ganglia circuits through the sensorimotor striatum. These effects were amplified when the motor training occurred under the influence of cocaine. It has been proposed that the transition from casual drug use to uncontrolled, compulsive drug taking involves aberrant motor learning and that this effect is mediated by drug-induced changes in learning mechanisms in the dorsal striatum (White, 1996; Berke and Hyman, 2000; Everitt et al, 2001; Hyman and Malenka, 2001). Future work will have to determine whether the cocaine effects on training-related molecular changes 
observed in our studies play a role in aberrant motor learning or other behavioral changes associated with drug addiction.

\section{ACKNOWLEDGEMENTS}

This work was supported by USPHS Grant DA015439. We thank Joel Beverley for excellent technical assistance and Dr Anthony West for helpful discussions.

\section{REFERENCES}

Albin RL, Young AB, Penney JB (1989). The functional anatomy of basal ganglia disorders. Trends Neurosci 12: 366-375.

Alexander GE, Crutcher MD, DeLong MR (1990). Basal gangliathalamocortical circuits: parallel substrates for motor, oculomotor, 'prefrontal' and 'limbic' functions. Prog Brain Res 85: 119-146.

Alexander GE, DeLong MR, Strick PL (1986). Parallel organization of functionally segregated circuits linking basal ganglia and cortex. Annu Rev Neurosci 9: 357-381.

Badiani A, Oates MM, Day HE, Watson SJ, Akil H, Robinson TE (1999). Environmental modulation of amphetamine-induced cfos expression in D1 versus D2 striatal neurons. Behav Brain Res 103: 203-209.

Bailey CH, Bartsch D, Kandel ER (1996). Toward a molecular definition of long-term memory storage. Proc Natl Acad Sci USA 93: $13445-13452$.

Bailey CH, Kandel ER (1993). Structural changes accompanying memory storage. Annu Rev Physiol 55: 397-426.

Barrot M, Abrous DN, Marinelli M, Rouge-Pont F, Le Moal M, Piazza PV (2001). Influence of glucocorticoids on dopaminergic transmission in the rat dorsolateral striatum. Eur J Neurosci 13: 812-818.

Berke JD, Hyman SE (2000). Addiction, dopamine, and the molecular mechanisms of memory. Neuron 25: 515-532.

Berretta S, Robertson HA, Graybiel AM (1992). Dopamine and glutamate agonists stimulate neuron-specific expression of Foslike protein in the striatum. J Neurophysiol 68: 767-777.

Brandon CL, Steiner H (2003). Repeated methylphenidate treatment in adolescent rats alters gene regulation in the striatum. Eur J Neurosci 18: 1584-1592.

Brasted PJ, Wise SP (2004). Comparison of learning-related neuronal activity in the dorsal premotor cortex and striatum. Eur J Neurosci 19: 721-740.

Brown EE, Robertson GS, Fibiger HC (1992). Evidence for conditional neuronal activation following exposure to a cocaine-paired environment: role of forebrain limbic structures. J Neurosci 12: 4112-4121.

Calabresi P, Pisani A, Mercuri NB, Bernardi G (1996). The corticostriatal projection: from synaptic plasticity to dysfunctions of the basal ganglia. Trends Neurosci 19: 19-24.

Carelli RM, Wolske M, West MO (1997). Loss of lever press-related firing of rat striatal forelimb neurons after repeated sessions in a lever pressing task. J Neurosci 17: 1804-1814.

Cenci MA, Björklund A (1993). Transection of corticostriatal afferents reduces amphetamine- and apomorphine-induced striatal Fos expression and turning behaviour in unilaterally 6-hydroxydopamine-lesioned rats. Eur J Neurosci 5: 1062-1070.

Cenci MA, Campbell K, Wictorin K, Björklund A (1992). Striatal cfos induction by cocaine or apomorphine occurs preferentially in output neurons projecting to the substantia nigra in the rat. Eur J Neurosci 4: 376-380.

Centonze D, Grande C, Saulle E, Martín AB, Gubellini P, Pavón N et al (2003). Distinct roles of D1 and D5 dopamine receptors in motor activity and striatal synaptic plasticity. J Neurosci 23: 8506-8512.

Centonze D, Picconi B, Gubellini P, Bernardi G, Calabresi P (2001). Dopaminergic control of synaptic plasticity in the dorsal striatum. Eur J Neurosci 13: 1071-1077.

Charpier S, Mahon S, Deniau JM (1999). In vivo induction of striatal long-term potentiation by low-frequency stimulation of the cerebral cortex. Neuroscience 91: 1209-1222.

Cole AJ, Bhat RV, Patt C, Worley PF, Baraban JM (1992). D dopamine receptor activation of multiple transcription factor genes in rat striatum. J Neurochem 58: 1420-1426.

Davis HP, Squire LR (1984). Protein synthesis and memory: a review. Psychol Bull 96: 518-559.

Drago J, Gerfen CR, Westphal H, Steiner H (1996). D1 dopamine receptor-deficient mouse: cocaine-induced regulation of immediate-early gene and substance $\mathrm{P}$ expression in the striatum. Neuroscience 74: 813-823.

Everitt BJ, Dickinson A, Robbins TW (2001). The neuropsychological basis of addictive behaviour. Brain Res Rev 36: 129-138.

Ferguson SM, Thomas MJ, Robinson TE (2004). Morphineinduced c-fos mRNA expression in striatofugal circuits: modulation by dose, environmental context, and drug history. Neuropsychopharmacology 29: 1664-1674.

Gerdeman GL, Partridge JG, Lupica CR, Lovinger DM (2003). It could be habit forming: drugs of abuse and striatal synaptic plasticity. Trends Neurosci 26: 184-192.

Gerfen CR, Wilson CJ (1996). The basal ganglia. In: Swanson LW, Björklund A, Hökfelt T (eds). Handbook of Chemical Neuroanatomy. Elsevier: Amsterdam. pp 371-468.

Graybiel AM (1995). Building action repertoires: memory and learning functions of the basal ganglia. Curr Opin Neurobiol 5: 733-741.

Graybiel AM, Canales JJ, Capper-Loup C (2000). Levodopainduced dyskinesias and dopamine-dependent stereotypies: a new hypothesis. Trends Neurosci 23: S71-S77.

Graybiel AM, Moratalla R, Robertson HA (1990). Amphetamine and cocaine induce drug-specific activation of the c-fos gene in striosome-matrix compartments and limbic subdivisions of the striatum. Proc Natl Acad Sci USA 87: 6912-6916.

Groenewegen HJ, Berendse HW, Wolters JG, Lohman AH (1990). The anatomical relationship of the prefrontal cortex with the striatopallidal system, the thalamus and the amygdala: evidence for a parallel organization. Prog Brain Res 85: $95-116$.

Haracz JL, Tschanz JT, Wang Z, White IM, Rebec GV (1993). Striatal single-unit responses to amphetamine and neuroleptics in freely moving rats. Neurosci Biobehav Rev 17: 1-12.

Harlan RE, Garcia MM (1998). Drugs of abuse and immediateearly genes in the forebrain. Mol Neurobiol 16: 221-267.

Hattori S, Naoi M, Nishino H (1994). Striatal dopamine turnover during treadmill running in the rat: relation to the speed of running. Brain Res Bull 35: 41-49.

Hyman SE (2005). Addiction: a disease of learning and memory. Am J Psychiatry 162: 1414-1422.

Hyman SE, Malenka RC (2001). Addiction and the brain: the neurobiology of compulsion and its persistence. Nat Rev Neurosci 2: 695-703.

Hyman SE, Nestler EJ (1996). Initiation and adaptation: a paradigm for understanding psychotropic drug action. Am J Psychiatry 153: 151-162.

Jog MS, Kubota Y, Connolly CI, Hillegaart V, Graybiel AM (1999). Building neural representations of habits. Science 286: 1745-1749.

Johansson B, Lindström K, Fredholm BB (1994). Differences in the regional and cellular localization of c-fos messenger RNA induced by amphetamine, cocaine and caffeine in the rat. Neuroscience 59: 837-849. 
Kauer JA (2004). Learning mechanisms in addiction: synaptic plasticity in the ventral tegmental area as a result of exposure to drugs of abuse. Annu Rev Physiol 66: 447-475.

Kelley AE (2004). Memory and addiction: shared neural circuitry and molecular mechanisms. Neuron 44: 161-179.

Kerr JN, Wickens JR (2001). Dopamine D-1/D-5 receptor activation is required for long-term potentiation in the rat neostriatum in vitro. J Neurophysiol 85: 117-124.

Kitsukawa T, Tomioka R, Utsumi H, Yanagihara D, Yamamori T (2002). Histochemical identification of neuronal processing involved in change of running pattern in mice. Soc Neurosci Abstr 28: 264.8 .

Kitsukawa T, Yanagihara D, Yamamori T (2004). Bilaterally projecting cortico-striatal pathway is activated on the stepping-pattern learning in mice. Soc Neurosci Abstr 30: 534.5.

Knowlton BJ, Mangels JA, Squire LR (1996). A neostriatal habit learning system in humans. Science 273: 1399-1402.

Kosofsky BE, Genova LM, Hyman SE (1995). Substance P phenotype defines specificity of c-fos induction by cocaine in developing rat striatum. J Comp Neurol 351: 41-50.

Kovacs KJ (1998). c-Fos as a transcription factor: a stressful (re)view from a functional map. Neurochem Int 33: 287-297.

Kuhar MJ, Pilotte NS (1996). Neurochemical changes in cocaine withdrawal. Trends Pharmacol Sci 17: 260-264.

Liste I, Guerra MJ, Caruncho HJ, Labandeira-Garcia JL (1997). Treadmill running induces striatal Fos expression via NMDA glutamate and dopamine receptors. Exp Brain Res 115: 458-468.

Liste I, Rodriguez-Pallares J, Caruncho HJ, Labandeira-Garcia JL (1999). Locomotor-activity-induced changes in striatal levels of preprotachykinin and preproenkephalin mRNA. Regulation by the dopaminergic and glutamatergic systems. Mol Brain Res 70: 74-83.

MacRae PG, Spirduso WW, Cartee GD, Farrar RP, Wilcox RE (1987). Endurance training effects on striatal D2 dopamine receptor binding and striatal dopamine metabolite levels. Neurosci Lett 79: 138-144.

Mahon S, Deniau JM, Charpier S (2004). Corticostriatal plasticity: life after the depression. Trends Neurosci 27: 460-467.

McCloskey DP, Adamo DS, Anderson BJ (2001). Exercise increases metabolic capacity in the motor cortex and striatum, but not in the hippocampus. Brain Res 891: 168-175.

Meeusen R, Smolders I, Sarre S, de Meirleir K, Keizer H, Serneels $M$ et al (1997). Endurance training effects on neurotransmitter release in rat striatum: an in vivo microdialysis study. Acta Physiol Scand 159: 335-341.

Meredith GE, Steiner H (2006). Amphetamine increases tyrosine kinase-B receptor expression in the dorsal striatum. Neuroreport (in press).

Mishkin M, Malamut B, Bachevalier J (1984). Memories and habits: two neural systems. In: McGaugh JL, Weinberger NM (eds). Neurobiology of Human Learning and Memory. Guildford Press: New York. pp 65-87.

Miyachi S, Hasegawa YT, Gerfen CR (2005). Coincident stimulation of convergent cortical inputs enhances immediate early gene induction in the striatum. Neuroscience 134: 1013-1022.

Miyachi S, Hikosaka O, Lu X (2002). Differential activation of monkey striatal neurons in the early and late stages of procedural learning. Exp Brain Res 146: 122-126.

Moratalla R, Xu M, Tonegawa S, Graybiel AM (1996). Cellular responses to psychomotor stimulant and neuroleptic drugs are abnormal in mice lacking the D1 dopamine receptor. Proc Natl Acad Sci USA 93: 14928-14933.

Moser MB (1999). Making more synapses: a way to store information? Cell Mol Life Sci 55: 593-600.

Neisewander JL, Baker DA, Fuchs RA, Tran-Nguyen LT, Palmer A, Marshall JF (2000). Fos protein expression and cocaine-seeking behavior in rats after exposure to a cocaine self-administration environment. J Neurosci 20: 798-805.
Nestler EJ (2001). Molecular basis of long-term plasticity underlying addiction. Nat Rev Neurosci 2: 119-128.

Nishioku T, Shimazoe T, Yamamoto Y, Nakanishi H, Watanabe S (1999). Expression of long-term potentiation of the striatum in methamphetamine-sensitized rats. Neurosci Lett 268: 81-84.

Pacak K, Palkovits M (2001). Stressor specificity of central neuroendocrine responses: implications for stress-related disorders. Endocr Rev 22: 502-548.

Packard MG, Knowlton BJ (2002). Learning and memory functions of the basal ganglia. Annu Rev Neurosci 25: 563-593.

Paxinos G, Watson C (1998). The Rat Brain in Stereotaxic Coordinates. Academic Press: New York.

Pierce RC, Kalivas PW (1997). A circuitry model of the expression of behavioral sensitization to amphetamine-like psychostimulants. Brain Res Rev 25: 192-216.

Reep RL, Cheatwood JL, Corwin JV (2003). The associative striatum: organization of cortical projections to the dorsocentral striatum in rats. J Comp Neurol 467: 271-292.

Reynolds JN, Hyland BI, Wickens JR (2001). A cellular mechanism of reward-related learning. Nature 413: 67-70.

Reynolds JN, Wickens JR (2002). Dopamine-dependent plasticity of corticostriatal synapses. Neural Netw 15: 507-521.

Robinson TE, Berridge KC (2000). The psychology and neurobiology of addiction: an incentive-sensitization view. Addiction 95(Suppl 2): S91-S117.

Saal D, Dong Y, Bonci A, Malenka RC (2003). Drugs of abuse and stress trigger a common synaptic adaptation in dopamine neurons. Neuron 37: 577-582.

Schultz W, Tremblay L, Hollerman JR (2003). Changes in behavior-related neuronal activity in the striatum during learning. Trends Neurosci 26: 321-328.

Senba E, Ueyama T (1997). Stress-induced expression of immediate early genes in the brain and peripheral organs of the rat. Neurosci Res 29: 183-207.

Sherwin CM (1998). Voluntary wheel running: a review and novel interpretation. Anim Behav 56: 11-27.

Steiner H, Gerfen CR (1993). Cocaine-induced c-fos messenger RNA is inversely related to dynorphin expression in striatum. J Neurosci 13: 5066-5081.

Steiner H, Gerfen CR (1995). Dynorphin opioid inhibition of cocaine-induced, D1 dopamine receptor-mediated immediateearly gene expression in the striatum. J Comp Neurol 353: 200-212.

Steiner H, Gerfen CR (1998). Role of dynorphin and enkephalin in the regulation of striatal output pathways and behavior. Exp Brain Res 123: 60-76.

Steiner H, Kitai ST (2000). Regulation of rat cortex function by D1 dopamine receptors in the striatum. J Neurosci 20: 5449-5460.

Stork O, Welzl H (1999). Memory formation and the regulation of gene expression. Cell Mol Life Sci 55: 575-592.

Thomas U (2002). Modulation of synaptic signalling complexes by Homer proteins. J Neurochem 81: 407-413.

Torres G, Horowitz JM (1999). Drugs of abuse and brain gene expression. Psychosom Med 61: 630-650.

Tschanz JT, Haracz JL, Griffith KE, Rebec GV (1991). Bilateral cortical ablations attenuate amphetamine-induced excitations of neostriatal motor-related neurons in freely moving rats. Neurosci Lett 134: 127-130.

Ungless MA, Whistler JL, Malenka RC, Bonci A (2001). Single cocaine exposure in vivo induces long-term potentiation in dopamine neurons. Nature 411: 583-587.

Uslaner JM, Crombag HS, Ferguson SM, Robinson TE (2003). Cocaine-induced psychomotor activity is associated with its ability to induce c-fos mRNA expression in the subthalamic nucleus: effects of dose and repeated treatment. Eur J Neurosci 17: $2180-2186$.

Vargo JM, Marshall JF (1995). Time-dependent changes in dopamine agonist-induced striatal Fos immunoreactivity are 
related to sensory neglect and its recovery after unilateral prefrontal cortex injury. Synapse 20: 305-315.

Werme M, Thoren P, Olson L, Brene S (2000). Running and cocaine both upregulate dynorphin mRNA in medial caudate putamen. Eur J Neurosci 12: 2967-2974.

West MO, Carelli RM, Pomerantz M, Cohen SM, Gardner JP, Chapin JK et al (1990). A region in the dorsolateral striatum of the rat exhibiting single-unit correlations with specific locomotor limb movements. J Neurophysiol 64: 1233-1246.

White FJ, Kalivas PW (1998). Neuroadaptations involved in amphetamine and cocaine addiction. Drug Alcohol Depend 51: 141-153.

White NM (1989). Reward or reinforcement: what's the difference? Neurosci Biobehav Rev 13: 181-186.

White NM (1996). Addictive drugs as reinforcers: multiple partial actions on memory systems. Addiction 91: 921-949.

Willuhn I, Steiner H (2005a). Motor learning-related gene regulation in the striatum: Effects of cocaine. In: Bolam JP, Ingham CA, Magill PJ (eds). The Basal Ganglia VIII. Plenum Press: New York. pp 197-207.

Willuhn I, Steiner H (2005b). Motor skill learning under the influence of cocaine: evidence for two distinct roles of D1 dopamine receptors. Soc Neurosci Abstr 31: 682.11.
Willuhn I, Sun W, Steiner H (2003). Topography of cocaineinduced gene regulation in the rat striatum: relationship to cortical inputs and role of behavioural context. Eur J Neurosci 17: $1053-1066$.

Wilson WM, Marsden CA (1995). Extracellular dopamine in the nucleus accumbens of the rat during treadmill running. Acta Physiol Scand 155: 465-466.

Wolf ME (1998). The role of excitatory amino acids in behavioral sensitization to psychomotor stimulants. Prog Neurobiol 54: 679-720.

Xiao B, Tu JC, Worley PF (2000). Homer: a link between neural activity and glutamate receptor function. Curr Opin Neurobiol 10: $370-374$

Yano M, Steiner H (2005a). Methylphenidate (Ritalin) induces Homer 1a and zif 268 expression in specific corticostriatal circuits. Neuroscience 132: 855-865.

Yano M, Steiner H (2005b). Topography of methylphenidate (Ritalin)-induced gene regulation in the striatum: differential effects on c-fos, substance P and opioid peptides. Neuropsychopharmacology 30: 901-915.

Young ST, Porrino LJ, Iadarola MJ (1991). Cocaine induces striatal c-Fos-immunoreactive proteins via dopaminergic $D_{1}$ receptors. Proc Natl Acad Sci USA 88: 1291-1295. 